\title{
Shuttlebox avoidance in Norway rats from infancy to maturity
}

\author{
RICHARD H. BAUER \\ Kansas State University, Manhattan, Kansas 66506
}

\begin{abstract}
Shuttlebox avoidance of Sprague-Dawley rats 15, 17, 21-22, 36-37, and 90-100 days old was examined. Avoidance of 15- and 17-day-old rats was lower than that of older animals. Avoidance improved markedly from 17 to 36 days of age but declined at 90 days of age. Behavioral and physiological bases for these findings are considered.
\end{abstract}

In a variety of behavioral situations, rats younger than approximately 30 days and adult rats with bilateral hippocampal ablations behave in a similar manner, but both are different from normal adults (Altman, Brunner, \& Bayer, 1973). The behavioral similarities of immature rats and adult hippocampal rats have been attributed to the finding that the hippocampus requires at least 30 days to develop (Altman et al., 1973). Since a number of reports indicate that shuttlebox acquisition is more rapid in adult rats with hippocampal ablations than in intact adult rats (Altman et al., 1973; Lovely, Grossen, Moot, Bauer, \& Peterson, 1971), it has been suggested that shuttlebox avoidance acquisition would be more rapid in immature rats than in intact adults (Altman et al., 1973).

On the other hand, active avoidance generally occurs earlier during development in relatively easy tasks than in more difficult ones (cf. Misanin, Nagy, Keiser, \& Bowen, 1971; Riccio, Rohrbaugh, \& Hodges, 1968; Thompson, Koenigsberg, \& Tennison, 1965). Since shuttlebox avoidance is relatively difficult for intact adults (Theios, Lynch, \& Lowe, 1966), on the basis of task difficulty, immature rats would be expected to acquire shuttlebox avoidance more slowly than adults.

The major purpose of the present study was to examine shuttlebox avoidance as a function of development. The task used in this experiment was very similar to one in which adult hippocampal rats acquire at a faster rate than normal adults (Lovely et al., 1971).

\section{METHOD}

\section{Animals}

The subjects were 15-, 17-, 21- to 22-, 36- to 37-, and 90to 100-day-old, experimentally naive, male Sprague-Dawley rats born and raised in a colony maintained by the Department of Immunology at the University of California, Los Angeles $(n=10$ per group). For brevity, only the youngest age of each group will be referred to hereafter.

The rats were randomly assigned to age groups with the

This research was supported by Mental Health Grant MH-24384-01. Requests for reprints should be sent to the Department of Psychology, Kansas State University, Manhattan, Kansas 66506. constraints that only one animal from each litter was tested at any one age and that eyes of the younger rats were open. The rats had free access to food (Wayne Mouse Breeder Blox, General Mills) and water throughout the experiment. The colony room had a 14-h light cycle from 6:00 a.m. to 8:00 p.m. and a mean temperature of $72^{\circ} \mathrm{F}$. Testing was conducted between 9:00 a.m. and $4: 00$ p.m.

\section{Apparatus}

The apparatus consisted of three completely automated shuttleboxes. The apparatus dimensions varied according to the approximate spine length of each age. The oldest group was trained in a $72 \times 14 \times 17 \mathrm{~cm}$ box with $.9-\mathrm{cm}$-diam bars placed $2.5 \mathrm{~cm}$ apart (center to center). The 36-day-old rats were trained in a $51 \times 10 \times 13 \mathrm{~cm}$ box with a floor of $.7-\mathrm{cm}$-diam bars placed $1.7 \mathrm{~cm}$ apart. Rats 21 days of age were trained in the same box as 36 -day-olds, but the length and width were reduced by $15 \%$ by inserting aluminum inner liners. Fifteen- and 17-day-old animals were tested in a $26 \times 6 \times 7 \mathrm{~cm}$ box with a grid floor composed of .4-cm-diam bars placed $1 \mathrm{~cm}$ apart.

The plywood walls of each box were covered with aluminum sheets, and the top was covered with a Plexiglas lid. The floors were composed of stainless steel rods mounted in Plexiglas. The floors were separate from the walls and pivoted at the center so the animal's weight tilted the floor. A microswitch was mounted on the outside wall and was opened or closed when the rat crossed the center. This switch led to a solid state circuit for programming the apparatus. General illumination was provided by a $15-\mathrm{W} 120-\mathrm{V}$ bulb mounted $40 \mathrm{~cm}$ above the grid floor. A $10-\mathrm{cm}$ speaker was centered $40 \mathrm{~cm}$ above the grid floor and provided a 75-dB SPL white-noise CS ( $8 \mathrm{~dB}$ above background, as measured by a Model 1551-B General Radio Corporation sound-level meter). Footshock of approximately $1.5 \mathrm{~mA}$ could be delivered to the floor and aluminum walls by a circuit described elsewhere (Lovely et al., 1971).

The shuttleboxes were placed inside a $90 \times 32 \times 57 \mathrm{~cm}$ sound-resistant box constructed of $2-\mathrm{cm}$ plywood lined with acoustical tile. The rats were observed through a small hole. The occurrence of the CS, US, and shuttle crossings were recorded on a three-channel event recorder.

\section{Procedure}

Rats trained at 15,17 , and 21 days of age were housed with their mothers and littermates in standard cages $(28 \times 23 \times 24 \mathrm{~cm})$ with sawdust shavings until trained, and they were returned immediately afterward. Animals trained at 36 days or older were weaned at 30 days of age, and two animals were housed in standard cages until tested. They were returned to the home cage immediately after testing.

The rats were adapted to the shuttlebox for $8 \mathrm{~min}$ before receiving a single session of 200 avoidance trials. The intertrial interval was variable, ranging from 20 to $90 \mathrm{sec}$, with a mean of 
$60 \mathrm{sec}$. The CS was presented for $10 \mathrm{sec}$ and was followed by the US if no avoidance response occurred within the CS-US interval. The CS and US remained on until the rat escaped or for a maximum of $20 \mathrm{sec}$. The CS and US terminated simultaneously with the escape response. The boxes were cleaned with a damp towel after each animal was trained.

\section{RESULTS}

Mean percentage avoidance in 10 trial blocks for each age is presented in Figure 1. Since there was heterogeneity of variance across trials, mean percentage avoidance for each block of 10 trials and each animal was subjected to an arcsin transformation. The transformed data were analyzed by a 5 (age) by 20 (trial blocks) mixed analysis of variance. This analysis showed that the main effects for age $[\mathrm{F}(4,45)=15.20, \mathrm{p}<.001]$ and trials $[F(19,855)=7.84, p<.001]$ were significant. The Age by Trials interaction was significant $[F(76,855)$ $=4.22, \mathrm{p}<.001]$, suggesting that across trials avoidance increased at a faster rate in older animals than in younger animals.

Comparisons between individual treatment means for the total 200 trials by Tukey's (a) test showed that 15- and 17-day-old rats were not significantly different from each other but that they made fewer avoidances than older animals $(p<.01)$. The 21 - and 90 -day-old groups were not significantly different from each other, but both groups were significantly lower than the 36-day-old group $(\mathrm{p}<.01)$.

Figure 2 shows the mean number of crossings per minute during adaptation. One-way analysis of variance indicated that there was a significant difference among the groups $[F(1,45)=4.99, \mathrm{p}<.05]$. Individual comparisons by Tukey's (a) test indicated that 15-day-old rats were significantly less active than older animals $(\mathrm{p}<.01)$. The 17-, 21-, and 90-day-old groups were not significantly different from each other but were significantly less active than the 36 -day-old group $(p<.05)$.

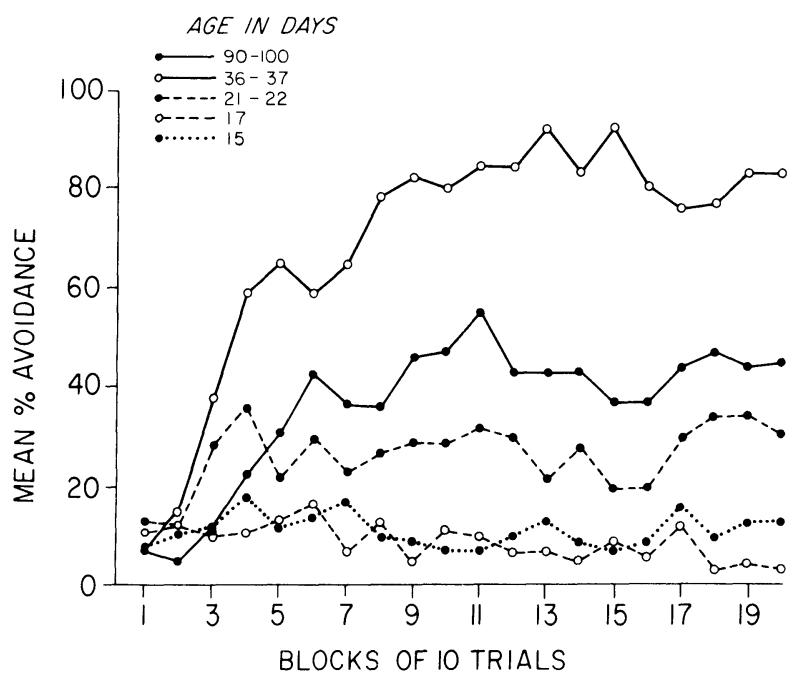

Figure 1. Mean percentage avoidance in $\mathbf{1 0}$ trial blocks for five different ages (standard errors of the mean ranged from 1.53 to 13.76 ).

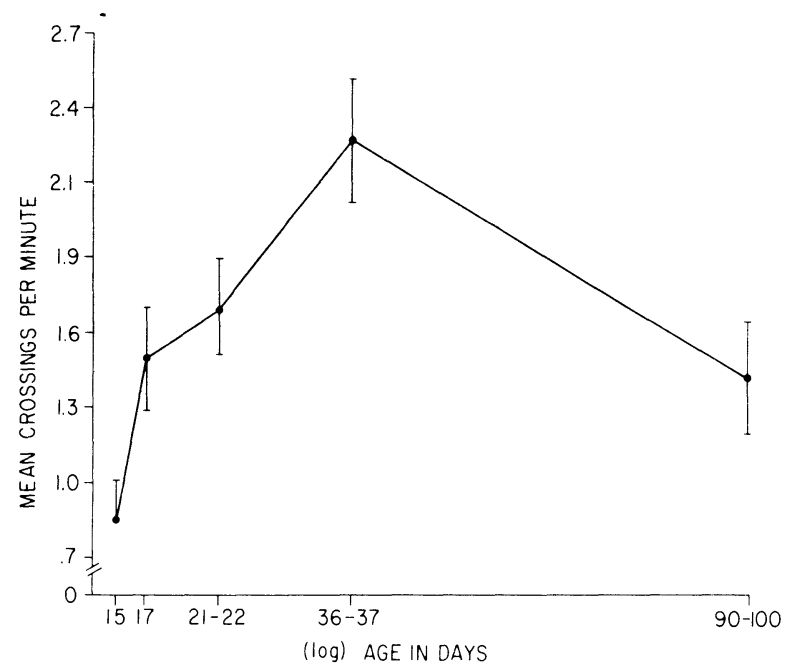

Figure 2. Mean ( \pm 1 SEM) shuttlebox crossings per minute during adaptation as a function of age.

The Pearson product-moment correlation between the total number of avoidance responses and activity during adaptation was significant $[\mathrm{r}(48)=.45, \mathrm{p}<.001]$.

One-way analysis of variance of the total number of intertrial responses showed that there was no significant difference among the five ages $[F(1,45)=1.25]$. There was no significant correlation between the total number of avoidance responses and the total number of intertrial responses $[\mathrm{r}(48)=.10]$.

\section{DISCUSSION}

The present results contradict the suggestion that two-way avoidance acquisition would be more rapid in immature rats than in adults (Altman et al., 1973). However, a number of other brain structures, such as the caudate and amygdala, develop at about the same rate as the hippocampus (Benjamins \& McKann, 1972; Lanier, Dunn, \& Van Hartesveldt, 1976), and in adults damage to these structures also alters shuttlebox avoidance (Bush, Lovely, \& Pagano, 1973; Kirby \& Polgar, 1974). Therefore, developmental changes in shuttle avoidance may be due to maturation in structures other than the hippocampus.

As compared with other avoidance tasks, two-way avoidance is relatively difficult for the rat, and task difficulty may be important for the low avoidance of immature rats. On a given shuttlebox trial, the animal is required to return to the place in which it has been shocked, and, therefore, there is an inherent passive avoidance component in this task. However, it appears unlikely that faster passive avoidance learning is responsible for the lower performance of immature rats, since passive avoidance learning is slower in immature rats than in adult rats (Altman et al., 1973; Riccio et al., 1968). Active avoidance is probably essential for shuttlebox acquisition, and some studies indicate that one-way active avoidance increases during maturation (Riccio et al., 1968; Thompson et al., 1965). Therefore, ontogeny of shuttlebox avoidance may be due to improvement in the active avoidance component of this task.

Active rats are reported to have an increased probability of making shuttle avoidance responses sooner than inactive rats (Kreickhaus, Miller, \& Zimmerman, 1965), and a significant correlation between avoidance and activity during adaptation was found in the present study. However, the correlation between avoidance and intertrial responses was not significant. Thus, it is not clear that age-related changes in locomotor activity can account for ontogeny of two-way avoidance. 
Responses elicited by UCSs are important for avoidance, in that avoidance is more rapid when these responses are compatible with the avoidance contingencies than when they are incompatible (Bolles, 1970). Behavioral observations indicated that the initial response of immature rats to each US was to jump up the walls or to attempt to squeeze through the grid bars. As avoidance began to appear as a function of age, these incompatible responses gradually disappeared and running was more prominent. Therefore, developmental changes in responses to footshock appear to be important for development of twoway avoidance.

\section{REFERENCES}

Altman, J., Brunner, R. L., \& Bayer, S. A. The hippocampus and behavior. Behavioral Biology, 1973, 8, 557-569.

Benjamins, J. A., \& McKann, G. M. Neurochemistry of development. In R. W. Albers, G. J. Siegel, R. Katzman, \& B. W. Arganoff (Eds.), Basic neurochemistry. Boston: Little, Brown, 1972.

Bolles, R. C. Species-specific defense reactions and avoidance learning. Psychological Review, 1970, 77, 32-48.

Bush, D. F., Lovely, R. H., \& Pagano, R. R. Injections of ACTH induce recovery from shuttle-box avoidance deficits in rats with amygdaloid lesions. Journal of Comparative and Physiological Psychology, 1973, 83, 169-172.

Krrby, R. J., \& Polgar, S. Active avoidance in the laboratory rat following lesions of the dorsal ventral caudate nucleus.
Physiological Psychology, 1974, 2, 301-306.

Kreickhaus, E. E., Miller, N. E., \& Zimmerman, P. Reduced freezing behavior and improvement of shock avoidance by $\mathrm{d}$-amphetamine. Journal of Comparative and Physiological Psychology, 1965, 60, 36-40.

Lanier, L. P., Dunn, A. J., \& Van Hartesveldt, C. Development of neurotransmitters and their function in brain. In S. Ehrenpresis \& I. J. Copin (Eds.), Reviews of neuroscience (Vol. 2). New York: Raven Press, 1976.

Lovely, R. H., Grossen, N. E., Moot, S. A., Bauer, R. H., \& Peterson, J. J. Hippocampal lesions and inhibition of avoidance behavior. Journal of Comparative and Physiological Psychology, 1971, 77, 345-352.

Misanin, J. R., Nagy, Z. M., Keiser, E. F., \& Bowen, W. Emergence of long-term memory in the neonatal rat. Journal of Comparative and Physiological Psychology, 1971, 77, 188-199.

Riccio, D., Rohrbaugh, M., \& Hodges, L. A. Developmental aspects of passive and active avoidance learning in rats. Developmental Psychobiology, 1968, 1, 108-111.

Theios, J., LynCh, A. D., \& Lowe, W. F. Differential effects of shock intensity on one-way and shuttle avoidance conditioning. Journal of Experimental Psychology, 1966, 72, 294-299.

Thompson, R. W., Koenigsberg, T. A., \& Tennison, J. C. Effects of age on learning and retention of an avoidance response in rats. Journal of Comparative and Physiological Psychology, $1965,60,457-459$.

(Received for publication September 21, 1979.) 